\title{
Failure to detect any effect of startbox delay on intertrial delayed-response learning
}

\author{
SAM REVUSKY, HARALD TAUKULIS, and CALVIN PEDDLE \\ Memorial University, St. John's, Newfoundland A1B 3X9, Canada
}

Rats were rewarded for running down a runway if the previous trial, over 16 min earlier, had terminated in a white plastic goalbox, but were not rewarded if the trial had terminated in a larger black wooden goalbox (or vice versa). Overall, the rats learned the discrimination, albeit poorly. There were six groups of two rats each; the factors were $0-, 10-$, and 30 -sec delays in the startbox and whether the black or white goalbox was $\mathrm{S}+$. Discrimination learning occurred under each of these conditions and, contrary to concurrent interference theory, was not noticeably affected by startbox delay.

Rats can predict what will happen on one trial on the basis of an event of the preceding trial, which may have terminated many minutes earlier. Demonstrations of this can be split into two paradigmatic categories. (1) In delayed-reward learning, the response is emitted on one trial but not rewarded until the following trial, when the rat is returned to the apparatus (Lett, 1973, 1975, in press; Denny, Note 1). (2) In delayed-response learning, the cue occurs at the end of a trial and controls behavior emitted on the following trial (Capaldi, 1971; Pschirrer, 1972; Revusky, 1977).

This paper deals with intertrial delayed-response learning. The most famous demonstration of this is the case in which rats predict the presence or absence of food reward on the basis of whether food was present on the preceding trial (Capaldi, 1971). The rat is rewarded on alternate runway trials and learns to run faster on rewarded than on unrewarded trials. Revusky (1974) showed that cues that are more arbitrary than reward or nonreward can function as differential stimuli in the delayed-response intertrial learning paradigm. He taught rats that running down a runway would be rewarded if the previous trial, over 4 min earlier, had terminated in a narrow white plastic goalbox, but that it would not be rewarded if the previous trial had terminated in a large black wooden goalbox (or vice versa). This was the only relationship between the goalboxes and reward. Each of four rats learned the discrimination, but only after about 300 trials. This is probably the slowest intertrial learning on record.

The present experiment was an attempt to explain this slow learning in terms of Revusky's $(1971,1977)$ concurrent interference theory. Central to this theory is the belief that traditional delay learning experiments ask animals to solve insoluble problems. That is, an animal in an ordinary environment is continually bombarded with a buzzing-booming confusion of sensory experience; it has no way of knowing that the experimenter has imbedded two arbitrary events in this confusion, separated them by a time delay during which the confusion continues, and will reward it for associating between these two reference events. Because the animal is asked to accomplish an impossible task, the results of traditional experiments cannot be taken as support for the traditional belief that delay learning is in principle impossible and only occurs in practice as a result of uncontrolled extraneous factors (Spence, 1947). Instead, Revusky (1971, 1977) takes the opposite position that associations over delays of several hours are possible in principle and only fail to occur in practice because of the operation of an extraneous factor, interference with the reference association (i.e., the association between the two reference events the experimenter has selected) by associations of the reference events with extraneous events that occur during the delay. For instance, an animal may fail to learn that Event A is connected with a delayed Event B, because it learns that $A$ is connected with something else that occurred during the delay, or it learns that something that occurred during the delay is responsible for B. Thus, for long-delay learning to occur, principles of selective association must overcome potential interference.

Revusky (1971) conjectured that the specific principle of selective association underlying intertrial associations is that animals cannot readily associate between events that occur in different situations. Thus, an animal ought not to be able to associate between reference events that occur in an experimental apparatus and those extraneous events that occur while it is in its home cage or in a carrying cage during the intertrial interval. Because of this, intertrial events that occur while the animal is absent from the apparatus cannot readily produce interference. However, if there is a delay inside the apparatus, the events taking place during the delay ought to produce interference. It so happened that Revusky (1974) inadvertently introduced such a delay by not raising the startbox gate on any trial until the rat had been in the startbox for $10 \mathrm{sec}$. This suggests the possibility that the slow learning was 
primarily due to the $10-\sec$ startbox delay, rather than to the 4-min intertrial interval.

We repeated Revusky's (1974) experiment, but varied the delay in the startbox for different groups. The delays were 0,10 , or $30 \mathrm{sec}$. We expected better learning than in Revusky's (1974) experiment with the 0 -sec delay, no learning with the 30-sec delay (on the basis of a finding by Grice, 1948), and learning as poor as that in Revusky's (1974) experiment for the 10-sec delay. Because we ran 12 rats in sequence, the minimum intertrial interval in the present experimert was $16 \mathrm{~min}$, as compared to 4 min in Revusky's experiment.

\section{METHOD}

In unspecified details, Revusky's (1974) method was used. Twelve male Wistar rats were maintained in white plastic home cages at $80 \%$ ad-lib weight. There were six groups of two rats each, based on the factorial combination of whether $\mathrm{S}+$ was the black goalbox or the white goalbox and whether the startbox delay was 0,10 , or $30 \mathrm{sec}$. The gray runway was made of Hunter components except for the black goalbox and the Plexiglas gates to the goalboxes. The black wooden goalbox measured $35.3 \times 13.0 \times 12.5 \mathrm{~cm}$ (length $\mathrm{x}$ width $\mathrm{x}$ height), which was larger than the white Plexiglas goalbox. Speeds were measured by photocells that fired when the rats were $7 \mathrm{~cm}$ into the 136-cm alley and $7 \mathrm{~cm}$ short of the goalbox.

\section{Pretraining}

There were 12 days with nine placements per day into the black and white goalboxes according to a sequence of 108 trials with the following properties. On half the placements, if the goalbox of the preceding trial had been $\mathrm{S}+, 10 \%$ weight/volume sugar solution was available for the first $10 \mathrm{sec}$ of the $30-\mathrm{sec}$ placement. During the remaining placements, when the preceding goalbox had been $\mathrm{S}_{-}$, an empty spout was available for the first $10 \mathrm{sec}$. Whether reward or nonreward was to be obtained on the first trial of any day depended on the goalbox used during the last trial of the preceding day. The sequence of goalbox placements was arranged so that $25 \%$ of the placements involved reward in the white goalbox, $25 \%$ involved reward in black, $25 \%$ involved nonreward in white, and $25 \%$ involved nonreward in black. Thus, rewarded trials were preceded by other rewarded trials as often as they were preceded by nonrewarded trials. After these restrictions, the sequence of 108 trials was randomized. Each rat in the experiment was in a different position in the sequence, so that there could not possibly have been any form of communication among rats about the discriminative contingencies. The minimum interval between goalbox placements was $11 \mathrm{~min}$.

\section{Training}

The 70 days of runway training were similar to pretraining except that the rats had to run through the alley to get to the goalbox; the startbox delay was introduced at this point, with the 0-sec delay implemented by raising the startbox gate just as the rat was being placed in the startbox. The minimum intertrial interval was $16-25 \mathrm{~min}$ except during the first 10 days, when it was usually over $25 \mathrm{~min}$.

\section{RESULTS}

Table 2 contains a traditional ANOVA in terms of running speeds, but first we will focus upon a method more directly concerned with discrimination learning. For each day, we obtained the mean running speed on rewarded and nonrewarded trials for each rat (omitting
Table 1

Analysis of Variance on $t$ Ratios

\begin{tabular}{lrrc}
\hline \multicolumn{1}{c}{ Source } & df & MS & F \\
\hline Between Subjects & & & \\
A: Different Delays & 2 & .360 & .23 \\
B: S+ (black or white) & 1 & 62.436 & $40.55^{* *}$ \\
A by B & 2 & 1.448 & .95 \\
Error & 6 & 1.540 & \\
Within Subjects & & & \\
C: Blocks & 6 & 5.504 & $6.31 * *$ \\
A by C & 12 & .881 & 1.01 \\
B by C & 6 & 1.566 & 1.79 \\
A by B by C & 12 & 2.387 & $2.62^{*}$ \\
Error & 36 & .873 & \\
\hline
\end{tabular}

${ }^{*} p<.02 \quad{ }^{* *} p<.001$

the first trial of each day). Then, in blocks of 10 days, we obtained a paired $t$ statistic for each rat. A positive $t$ indicated that the rat ran faster on rewarded than on nonrewarded trials, while a negative $t$ indicated the opposite. We used these $t$ ratios as scores in a 3 by 2 by 7 (startbox delay by whether black or white was S+ by blocks) ANOVA, as shown in Table 1. Contrary to our original hypothesis, Table 1 shows no effect of the startbox delays on discrimination learning either as a main effect or as an interaction, except that the triple interaction was significant $(p<.02)$; we found no scientifically meaningful effect corresponding to the triple interaction, and since $p>.10$ for this interaction if adjustment is made for experimentwise error, we suspect that it is a sampling error.

Two effects in Table 1 were highly significant and are elucidated by Figure 1, which graphs mean $t$ ratios over blocks, collapsing results over the nonsignificant startbox delay factor. The significant $\mathrm{C}$ effect (blocks) in

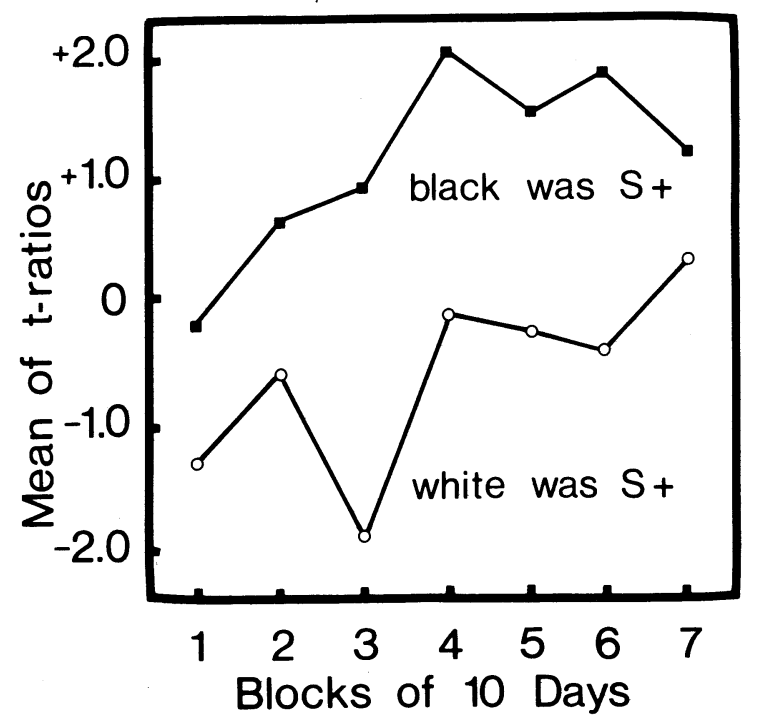

Figure 1. The course of discrimination learning depending on which goalbox from the preceding trial was $S+$. The data are expressed in terms of $t$ ratios that are positive if the rats ran faster on rewarded than on nonrewarded trials and negative if they did the opposite. 
Table 1 is reflected in the rise of the curves of Figure 1 over blocks and is evidence that discrimination learning occurred; that is, there was an increasing tendency over blocks for the rats to run faster on rewarded trials than on nonrewarded trials. The significant B effect in Table 1 is reflected in Figure 1 in the fact that the black $\mathrm{S}+$ curve was higher throughout than the white S+ curve. This effect was not due to learning but was due to an inexplicable tendency of the rats to run faster after trials terminating in the black goalbox than after trials terminating in the white goalbox.

If the running speeds of the rats were not related to the type of goalbox used on the preceding trial, the obtained $t$ ratios would approximate the chance distribution of $t(9)$ due to the experimental randomization of $\mathrm{S}+$ and $\mathrm{S}-$ cues. One can infer from this that the mean of the $t$ ratios over the 12 rats for each block multiplied by $\sqrt{\mathrm{n}}=\sqrt{12}$ has $\mathrm{t}(108)$ under the null hypothesis. By this criterion, the discrimination performance of all 12 rats taken together was significantly poorer than chance on the first block and significantly better than chance during Blocks $4,5,6$, and 7 (ps $<.05)$. In other words, in Block 1 speeds averaged faster on nonrewarded than on rewarded trials, while in Blocks $4,5,6$, and 7 , the opposite was true. The poorer-than-chance performance in Block 1 probably means that by a random sampling error, the rats most likely to run fast after black goalbox trials were assigned to white $\mathrm{S}+$ groups. If so, the present results are biased in a conservative direction. In all events, the $t$ ratios in Figure 1 for the white S+ rats were significantly lower than chance during Blocks 1 and 3 and never became significantly higher than chance.

Learning at the .01 level occurred under each cue and delay condition. The evidence is a progressive increase in the size of the $t$ ratios over blocks, as indicated by the $t$ test for linear trend based on the within-subjects error term of Table 1 . Considering only the four rats subjected to the 0-sec delay, $\mathrm{t}(36)=2.72$; at $10 \mathrm{sec}, \mathrm{t}(36)=3.15$; at $30 \mathrm{sec}, \mathrm{t}(36)=2.66$. Considering only the six black $\mathrm{S}+$ rats, $t(36)=3.61$; for the white $S+$ rats, $t(36)=3.35$.

By strict statistical criteria, the ANOVA in Table 1 is a better analysis of discrimination learning than the ANOVA on running speeds shown in Table 2, which is added to confirm the earlier result in more traditional terms. The $\mathrm{D}$ factor in Table 2 is whether the trial was $\mathrm{S}+$ or $\mathrm{S}-$; this is not present in Table 1 because the factor had been collapsed through the use of $t$ ratios. Each $F$ ratio in Table 1 corresponds to the $F$ ratio for an interaction with $D$ in Table 2, and the reader may confirm that both ANOVAs yield similar statistical decisions. The following additional significant results in Table 2 have no counterpart in Table 1. The significant A factor occurred because running speeds varied as an inverse function of the startbox delay; this means that although the discrimination was learned at each delay, we cannot meaningfully compare how well the discrimination was learned at different delays. The significant $\mathrm{C}$ factor reflects the
Table 2

Analysis of Variance on Running Speeds

\begin{tabular}{lrcc}
\hline \multicolumn{1}{c}{ Source } & df & MS & F \\
\hline Between Subjects & & & \\
A: Different Delays & 2 & .4282 & $8.27 *$ \\
B: S+ (black or white) & 1 & .2981 & 5.76 \\
A by B & 2 & .2578 & 4.98 \\
Error & 6 & .0518 & \\
Within Subjects & & & \\
C: Blocks & 6 & .1317 & $16.91^{* *}$ \\
A by C & 12 & .0052 & .66 \\
B by C & 6 & .0062 & .80 \\
A by B by C & 12 & .0071 & .91 \\
Error & 36 & .0078 & \\
D: Cue (correct or incorrect) & 1 & .0012 & 3.83 \\
A by D & 2 & .0001 & .36 \\
B by D & 1 & .0138 & $43.48 * *$ \\
A by B by D & 2 & .0004 & 1.15 \\
Error & 6 & .0003 & \\
C by D & 6 & .0015 & $7.84 * *$ \\
A by C by D & 12 & .0002 & 1.09 \\
B by C by D & 6 & .0004 & 2.19 \\
A by B by C by D & 12 & .0004 & $2.22^{*}$ \\
Error & 36 & .0002 & \\
\hline
\end{tabular}

${ }^{*} p<.05 \quad{ }^{* *} p<.001$

increase in running speeds after the first block, apparent in Figure 2, which shows the running speed data corresponding to the $t$ ratios of Figure 1. The $D$ effect in Table 2 is significant only at the one-tailed .05 level. However, the appropriate test for learning in Table 2 is the $\mathrm{C}$ by $\mathrm{D}$ interaction, which corresponds to the $\mathrm{C}$ effect in Table 1.

\section{DISCUSSION}

According to concurrent interference theory (Revusky, 1971, 1977), long-delay intertrial associations occur because the animals are absent from the apparatus during the delay; hence extraneous events that occur during the delay cannot readily

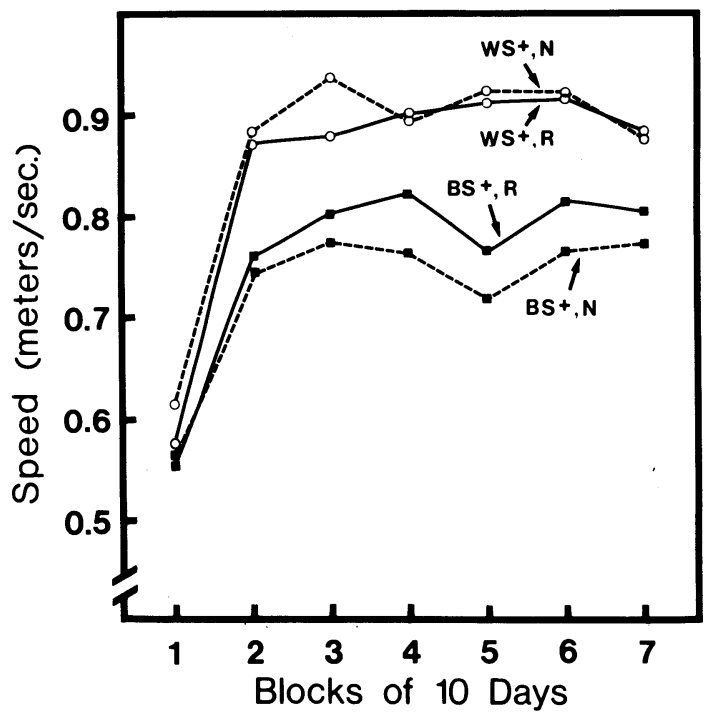

Figure 2. The course of discrimination learning in terms of running speed on rewarded $(R)$ and nonrewarded $(N)$ trials when either black (B) or white (W) served as S+. 
become associated with reference events that occur in the apparatus. The delay gradients of traditional experiments are short because the animals remain in the apparatus during the delay and can associate extraneous events that occur during the delay with the events of the reference association. By this reasoning, a startbox delay should produce a sharp gradient of interference because it occurs in the apparatus, and rats subjected to a 30-sec startbox delay ought not to learn the discrimination. That they did learn is damaging to concurrent interference theory.

The learning by the 30 -sec-delay rats also is not consistent with the results of intertrial delayed-reward experiments, in which rats make a response on one trial and are rewarded for it on the following trial. Lett (1975) showed that rats delayed in the apparatus endbox for $30 \mathrm{sec}$ prior to the intertrial interval did not learn. Barnes (cited by Lett, in press) showed that learning was prevented by delaying reward for $30 \mathrm{sec}$ after the intertrial interval while the rat waited in the startbox of the apparatus. We find the Barnes and Lett results more reasonable than the results reported here. The present occurrence of learning with a 30 -sec delay in the apparatus is impossible according to every known theory of delay learning, not just concurrent interference theory. Our guess is that an unknown element in the experimental situation created selective association between the goalbox cue and the outcome of the following trial and thus overcame the interference produced by the startbox events. If this is true, the present results fit in with Revusky's $(1971,1977)$ general insistence that principles of selective association underlie long-delay learning, even though they disprove the details of his specific analysis of intertrial associations.

Finally, we discuss two matters of minor theoretical importance. (1) Like the man not impressed by the dog that played chess because the dog usually lost, some readers may wish to pooh-pooh the present results because learning was weak and occurred very slowly. The weakness of the learning is indeed very evident in Figure 2, but this is not the issue. The issue is that learning occurred with a 30 -sec startbox delay, even though it cannot be explained in theoretical terms.

(2) In a later experiment, we tried to replicate the present experiment under conditions in which the black goalbox was made of the same material and had the same dimensions as the white goalbox. We obtained no learning, despite a reduction in the intertrial interval to $2-3 \mathrm{~min}$. Hence, brightness alone is not an adequate cue under our conditions.

\section{REFERENCE NOTE}

1. Denny, M. R. Recent explorations with a T-maze: Women's lib, long delays and all that. Presidential address to the 40th annual meeting of the Midwestern Psychological Association, Chicago, 1974.

\section{REFERENCES}

Capaldi, E. J. Memory and learning: A sequential viewpoint. In W. K. Honig \& P. H. R. James (Eds.), Animal memory. New York, Academic Press, 1971.

GRICE, G. R. The relation of secondary reinforcement to delayed reward in visual discrimination learning. Journal of Experimental Psychology, 1948, 37, 377-392.

LETT, B. T. Delayed reward learning: Disproof of the traditional theory. Learning and Motivation, 1973, 4, 237-246.

LETT, B. T. Long-delay learning in the T-maze. Learning and Motivation, 1975, 6, 80-90.

LETT, B. T. Long-delay learning: Implications for learning and memory theory. In N. S. Sutherland (Ed.), Tutorial essays in experimental psychology II. Potomac, Md: Erlbaum, in press.

Pschirrer, M. E. P. Goal events as discriminative stimuli over extended intertrial intervals. Journal of Experimental Psychology, 1972, 96, 425-432.

REVusKy, $S$. The role of interference in association over a delay. In W. K. Honig \& P. H. R. James (Eds.), Animal memory. New York, Academic Press, 1971.

Revusky, S. Long-delay learning in rats: A black-white discrimination. Bulletin of the Psychonomic Society, 1974, $4,526-528$

Revusky, S. The concurrent interference theory of delay learning. In M. Domjan, L. M. Barker, \& M. Best (Eds.), Learning mechanisms in food selection. Waco, Tex: Baylor University Press, 1977.

SPENCE, K. W. The role of secondary reinforcement in delayed reward learning. Psychological Review, 1947, 54, 1-8.

(Received for publication August 14, 1978.) 